\title{
The fusion pores of $\mathrm{Ca}^{2+-t r i g g e r e d ~ e x o c y t o s i s ~}$
}

\author{
Meyer B Jackson ${ }^{1}$ and Edwin R Chapman ${ }^{1,2}$ \\ ${ }^{1}$ Department of Physiology, University of Wisconsin School of Medicine and Public Health, 1300 \\ University Avenue, Madison, Wisconsin 53706, USA \\ 2 Howard Hughes Medical Institute, SMI 12e7, University of Wisconsin School of Medicine and \\ Public Health, 1300 University Avenue, Madison, Wisconsin 53706, USA
}

\begin{abstract}
The aqueous compartment inside a vesicle makes its first connection with the extracellular fluid through an intermediate structure termed the exocytotic fusion pore. Progress in exocytosis can be measured in terms of the formation and growth of the fusion pore. The fusion pore has become a major focus of research in exocytosis; sensitive biophysical measurements have provided various glimpses of what it looks like and how it behaves. Some of the principal questions about the molecular mechanism of exocytosis can be cast explicitly in terms of properties and transitions of fusion pores. This Review will present current knowledge about fusion pores in $\mathrm{Ca}^{2+}$-triggered exocytosis, highlight recent advances and relate questions about fusion pores to broader issues concerning how cells regulate exocytosis and how nerve terminals release neurotransmitter.
\end{abstract}

During exocytosis, the merger of two biological membranes is accompanied by the mixing of the two aqueous compartments delimited by those membranes. Thus, a fluid connection forms between the two aqueous compartments at a distinct time. This connection starts out as a microscopic water-filled passage with a long narrow shape that evokes the image of a pore. The formation of the fusion pore marks a well-defined stage in the fusion process that can be studied experimentally. Likewise, the merger of the two fusing membranes marks a well-defined stage in the fusion process, which can also be studied experimentally. These two processes, aqueous content mixing and membrane merger, need not occur simultaneously, and, as will be discussed in detail below, different models of membrane fusion make different predictions about the sequence of these two events. Furthermore, since the fusion pore emerges as a structure of molecular dimensions within a specialized contact between two fusing membranes, studying the structure and dynamics of the fusion pore reveals the process of exocytosis at a fundamental level.

Electron microscopy provided the first images of fusion pores with diameters of $\sim 50 \mathrm{~nm}$, but it was pointed out that these pores could have grown from something smaller1,2. Electrical measurements captured fusion intermediates with conductances ranging from 20 to $330 \mathrm{pS}$, and from these values one can estimate a fusion pore diameter of on the order of $\sim 1 \mathrm{~nm}$ (refs. $3^{-5}$ ). The structures inferred from these electrical measurements are good candidates for early-stage fusion pores. In addition to conducting ions, fusion pores also pass small neurotransmitters, and amperometric recording has revealed the flux of some of these molecules6 $6^{-8}$. Reports vary as to whether the initial fusion pore is well-defined and stable 9,10 , or noisy and chaotic1 $11^{-1}$. Thus, it is small and has protein-like dimensions, but it is not clear whether it can maintain the kind of rigid conducting state characteristic of proteinaceous ion channels.

Correspondence should be addressed to M.B.J. (mjackson@physiology.wisc.edu) or E.R.C. (chapman@physiology.wisc.edu).

Reprints and permissions information is available online at http://npg.nature.com/reprintsandpermissions/ 
Capacitance measurements have shown that fusion pore opening is a reversible process $4,6,14^{-} 17$, and amperometry has confirmed these observations $6,13,18,19$. These studies define the fusion pore as a metastable intermediate that can evolve in two distinct ways. Upon formation, a fusion pore is not absolutely committed to growth, and the vesicle is not absolutely committed to collapse into the plasma membrane. Vesicles can take an alternative route, pulling back from the plasma membrane intact, possibly with some neurotransmitter remaining inside. The idea that vesicles can engage in a transient exocytotic contact with the plasma membrane while preserving their integrity had an early incarnation as a mechanism of efficient membrane recycling at synapses20. Thus, we can envision two distinct modes of release21, 'full fusion' and 'kiss-and-run', with the fusion pore as the most likely bifurcation point. This gives the fusion pore a critical role as the structure that dictates the nature of the release process.

\section{Two contrasting models}

Models of exocytosis fall into two distinct classes, depending on whether the fusion pore is lined by protein or lipid3. Models with proteinaceous fusion pores invoke a gap junctionlike channel that spans the lipid bilayers of both the plasma and vesicular membranes (Fig. 1a). The pore is formed as proteins from the vesicular and target membranes associate (Fig. 1a, ii). Fusion pore opening in this model is viewed as a conformational transition of this protein complex (Fig. 1a, iii). From the open fusion pore state, a second transition must occur in which the fusion pore dilates as lipid replaces protein (Fig. 1a, iv). This dilation step must occur for the two bilayers to merge, but no satisfactory mechanism for this dilation step has been proposed. The open state of a proteinaceous fusion pore should be fairly rigid, like an open ion channel. After dilation has started, the incorporation of lipid would make the structure more fluid. For proteinaceous fusion pore models, aqueouscontent mixing generally precedes membrane mixing, although the formal possibility of a contiguous lipid pathway around a proteinaceous pore cannot be ruled out, and this could provide a way for the outer leaflets to mix before pore opening22. (With regard to the two leaflets of the two fusing lipid bilayers, the terms 'outer' and 'inner' derive from the case of two fusing vesicles, wherein the inner leaflets face the vesicle lumen and the outer leaflets face one another.)

An initial fusion pore composed of lipid invokes a very different mechanism of exocytosis (Fig. 1b). The prevailing model for a lipidic fusion pore begins with the formation of a stalk between the outer leaflets of the fusing lipid bilayers 23 (Fig. 1b, ii). These two merged leaflets then pull back to form a hemifusion diaphragm in which a lipid bilayer patch forms between the inner leaflets of the two membranes (Fig. 1b, iii). A lipidic pore then forms in the single bilayer of the hemifusion intermediate (Fig. 1b, iv). Although lipid bilayers do not readily form pores, the pulling back of the inner leaflets would expand and stress the nascent boundary bilayer; energetic calculations indicate that this stress could provide sufficient energy to create a pore23. The structure of this lipidic pore should be less rigid and fluctuate more readily. According to the lipid-stalk-hemifusion model (Fig. 1b), the outer leaflets mix before the fluid content; the onset of aqueous-compartment mixing coincides with the onset of inner-leaflet mixing.

Protein-free lipid bilayers can fuse under a variety of experimental conditions, and when they do, the reaction follows the sequence illustrated in Figure 1b (refs. 24,25). Furthermore, lipid bilayers can form stalk-like structures (Fig. 1b, ii) as water is removed26. Recombinant SNARE proteins reconstituted into liposomes are able to mediate membrane fusion in vitro27, and hemifusion intermediates have been inferred from the observation that the outer leaflets of the bilayer mix before the inner leaflets in fusion mediated by a variety of SNAREs $28^{-} 31$. Isolated yeast vacuoles fuse with one another, and they have been used as 
an in vitro system in which these ideas can be extended to a biological membrane.

Experiments based on very different methodological approaches have shown that when yeast vacuoles fuse the lipid bilayers mix before the aqueous contents $32^{-} 34$. However, these studies did not directly address the issue of hemifusion because the experiments did not resolve outer and inner leaflet mixing. Furthermore, it is not clear that the lipid mixing revealed in these experiments reflects a productive intermediate on the way to full fusion rather than a dead-end side reaction 35,36 .

The stalk model describes much of what is seen when a viral envelope fuses with a cell's plasma membrane37,38. Studies of viral fusion have shown that modifying the form of membrane attachment of a fusogenic protein (such as by replacing the membrane-spanning segment by a glycosyl phosphatidylinositol anchor) favors the formation of a hemifusion diaphragm39; pores can form in this metastable intermediate state, but not nearly as easily as with the wild-type protein, and pore enlargement is impaired40,41. Fluorescent lipids migrate between the membranes of fusing cells after the opening of a fusion pore 42,43 , but conditions can be found that reverse this sequence 37,44 .

In summary, although questions remain, most of the evidence favors lipidic pores in lipid bilayer fusion in vitro and during viral infection. In these forms of fusion, intermediates resembling those illustrated in Figure 1b may well come into play. Both the proteinaceous and lipidic fusion pore models have been invoked in experiments on $\mathrm{Ca}^{2+}$-triggered exocytosis in endocrine cells and neurons, and we will now discuss this work.

\section{Membrane transfer during $\mathrm{Ca}^{2+-t r i g g e r e d ~ f u s i o n ~}$}

Capacitance recordings in a variety of cell types have indicated that an upward step in capacitance is rapidly followed by a downward step, indicating that fusion pore opening is reversible ${ }^{1} 1^{-}$16. In the fusion of dense-core vesicles and microvesicles in rat posterior pituitary nerve terminals4, as well as the small granules of human neutrophils45, the upward step is matched precisely by a downward step, suggesting that the fusion pore acts as a barrier to bulk membrane flow between the vesicular and plasma membranes. However, the largest exocytosis steps in mast cells during guanine nucleotide-stimulated secretion are not precisely compensated by the ensuing endocytosis step; some membrane mixing occurs in such processes, so these fusion pores probably contain lipid46. The participation of lipid in mast cell fusion pores is further supported by a marked decline in the rate of fusion pore closure with decreasing temperature47. This sudden change in temperature dependence is reminiscent of a lipid-fluidity phase transition.

A study of $\mathrm{Ca}^{2+}$-triggered exocytosis from PC12 cells used two labels, GFP-phogrin and the styryl dye FM4-64, to explore the fate of the secretory granule membrane after exocytosis48. FM4-64 fluorescence decreases when a granule fuses, as the dye escapes to the extracellular fluid. GFP-phogrin fluorescence goes up, because the acidic environment inside a vesicle suppresses the fluorescence of GFP. After fusion, the increased GFP signal reverses by two mechanisms. With full fusion, the GFP-phogrin can spread out by lateral diffusion through the plasma membrane. Alternatively, with kiss-and-run, the GFP-phogrin can be internalized and repackaged in an acidic environment. (The addition of $\mathrm{NH}_{4} \mathrm{Cl}$ distinguishes between these two possibilities because it raises the intravesicular $\mathrm{pH}$ and recovers a point source of fluorescence.) Regardless of the fate of GFP-phogrin, a similar amount of FM4-64 dye is lost48. The loss of FM4-64 during events that terminate by repackaging GFP-phogrin suggested that the fusion pore provides a route for mixing of the vesicular and plasma membranes. However, movement of FM4-64 through the aqueous lumen of the pore is difficult to rule out completely. For the closely related dye FM1-43, the 
dissociation rate constant from lipid bilayers is on the order of $300 \mathrm{~s}^{-1}$ (ref. 49), so even a fairly short-lived aqueous channel could allow a considerable amount of destaining.

In summary, some experiments have suggested that membrane can move through a fusion pore and others have suggested the opposite. In the experiments showing membrane movement, it is not clear whether the fusion pore was in its earliest state of inception, or, alternatively, in some advanced, partially dilated state. Thus, the lipidic pores inferred from these studies do not rule out a proteinaceous pore at an earlier point in time. Both models posit lipid mixing during pore growth. Likewise, pore closure does not mean that the pore is proteinaceous because lipidic pores can also close24.

The studies showing no membrane movement are also not conclusive. Because a proteinaceous pore should obstruct flow, membrane movement is a sufficient criterion for a lipidic pathway between two membranes. But if the forces of membrane tension are well balanced between the two compartments, then there would be a small amount of diffusive transfer without bulk flow. Thus, membrane movement is not a necessary criterion for lipidic pores.

\section{Mutagenesis and putative pore proteins}

To contribute structurally to a fusion pore, a protein should have one or more transmembrane segments. Many of the proteins implicated in exocytosis harbor hydrophobic segments capable of forming membrane spanning $\alpha$-helices. In addition to the t-SNARE syntaxin and the v-SNARE synaptobrevin, the integral membrane proteins synaptotagmin, synaptophysin, and innumerable ion channels, pumps and transporters harbor structural motifs that could participate in the formation of a proteinaceous fusion pore.

Involvement of syntaxin in a proteinaceous fusion pore was tested in experiments on $\mathrm{Ca}^{2+}$ triggered exocytosis from PC12 cells. Amperometric measurements of the flux of norepinephrine through individual fusion pores provide an index of pore size. To test the hypothesis that the membrane anchor of syntaxin is a structural component of the fusion pore, mutations were introduced that altered the size of various residues50. At three out of sixteen locations, a bulky tryptophan replacement reduces fusion pore flux. Making more room by replacement with glycine enhances fusion pore flux, and changing the charge by replacement with acidic or basic residues enhances or reduces flux in a manner expected for electrostatic interactions with positively charged norepinephrine51. Selected tryptophan mutations were also tested in conductance measurements, and those mutations that reduce norepinephrine flux also reduce the ionic conductance of the fusion pore50. The three mutations in the syntaxin membrane anchor that influence fusion pore flux and conductance fall along one face of a putative $\alpha$-helix. Mutations that alter the flux through the fusion pore in this manner are rare; many mutations in the SNARE motifs of syntaxin, synaptobrevin and SNAP-25 have no effect9. These experiments suggest that the membrane anchor of syntaxin lines the walls of the fusion pore through the plasma membrane (Fig. 2). Cyclindependent kinase- 5 activity also influences norepinephrine flux through fusion pores, and an interaction with syntaxin has been proposed as a possible origin of this effect52.

The obvious partner for a fusion pore through the synaptic vesicle is synaptobrevin. This protein has a hydrophobic putative $\alpha$-helical segment that could span the vesicular membrane and complete the fusion pore so that it spans both bilayers. This hypothesis has yet to be tested, and further protein components of the fusion pore have not been identified. It must be mentioned that the presence of a protein in the fusion pore does not rigorously exclude the existence of lipid as an additional structural component. 


\section{Fusion pore transitions}

The fusion pore reports key structural transitions that occur during exocytosis, so studies of fusion pores can probe the kinetic mechanism of membrane fusion. Experimentally, we can observe when fusion pores open, close and dilate. If a molecular manipulation reduces exocytosis but leaves fusion pore closing and dilation unchanged, this implicates the targeted molecules in a step that precedes fusion pore opening. This still leaves a broad range of possibilities, starting from vesicle mobilization and proceeding to docking, priming, fusion pore assembly and the final structural transition that produces an open fusion pore. A large body of work in chromaffin cells and PC12 cells, using amperometry and capacitance recording to resolve the sequence of fusion pore transitions in single-vesicle release events, has addressed how various molecules function in different stages of exocytosis.

A number of proteins have been implicated in pre-fusion-pore steps of exocytosis, including the synaptic SNAREs9 $53^{-} 55$, complexin II (ref. 56), and tomosyn57,58. Some manipulations of these proteins reduce the frequency of vesicle fusion events but do not alter fusion pore lifetime. Many other molecular manipulations alter the stability of fusion pores. These proteins are more likely to play a role in the actual membrane remodeling process of exocytosis. Thus, the synaptic SNAREs, for which roles in steps leading to fusion pores were just noted, also can influence fusion pore lifetime9,59. Overexpressing different synaptotagmin isoforms and mutants can make fusion pores more stable or less stable $18,19,60,61$, and amisyn stabilizes open fusion pores62. It is thus possible that these proteins help catalyze the structural transitions of the fusion complex during key steps in the merger of the vesicular and plasma membranes.

In the case of synaptotagmin I, parallel experiments with varying $\mathrm{Ca}^{2+}$ concentrations and mutations in the $\mathrm{Ca}^{2+}$-binding sites support a role for $\mathrm{Ca}^{2+}$ binding as the trigger of both a pre-fusion pore step and the transition of an open fusion pore to a dilating fusion pore 19 . Furthermore, mutations that selectively impair synaptotagmin I binding to SNAREs destabilize open fusion pores61. These results suggest that a synaptotagmin-SNARE complex formed during $\mathrm{Ca}^{2+}$-triggered exocytosis catalyzes the opening of fusion pores and then stabilizes them by preventing them from returning to a closed state. Mutations in the $\mathrm{Ca}^{2+}$-binding sites of synaptotagmin I and IV also alter the rate with which open fusion pores close and influence the choice between full fusion versus kiss-and-run18,19.

The validity of interpreting changes in fusion pore kinetics in terms of functional transitions of the exocytotic apparatus has been complicated by the discovery that changing the size of a vesicle affects its fusion pore. Altering the amount of transmitter loaded into a vesicle alters its size and, unexpectedly, alters fusion pore stability such that larger vesicles produce longer-lasting fusion pores and smaller vesicles produced shorter-lived fusion pores63. Future studies of fusion pore kinetics will have to control for these effects by checking vesicle size or content. This result indicates that there may be extra physical determinants of fusion pore stability, and a better understanding of these effects will no doubt aid efforts to use fusion pores to study the molecular mechanism of exocytosis. We also note that proteins such as Munc18 (refs. 64,65), cysteine string proteins66, complexin II (ref. 67) and myosin II (ref. 68) alter release kinetics after the fusion pore has started to dilate. Although these effects have been interpreted in terms of fusion pore transitions, the weak temperature dependence of kinetic processes at this late stage of release argues against major membrane remodeling steps as limiting processes during release following fusion pore dilation 10 .

\section{Synaptic transmission}

Probing fusion pores in synapses has proven far more difficult than in endocrine cells. An indirect approach has focused on the kinetics of vesicle recycling. A membrane-bound, 
fluorescent $\mathrm{pH}$ sensor targeted to vesicles increases its fluorescence during exocytosis because of the higher $\mathrm{pH}$ of extracellular fluid. Fluorescence then declines as the label is reinternalized into an acidic compartment, and this decay follows a single exponential curve with a time constant of 14-15 s (refs. 69,70; but see also ref. 71). This argues against kissand-run because kiss-and-run should follow a kinetically detectable, distinct pathway. The interpretation of these experiments rests on the assumption that the fluorescence decrease reflects the internalization of the same proteins that produced the fluorescence increase. However, the plasma membrane has a standing pool of vesicular proteins, and when their labels are removed by proteolytic cleavage, much of the compensatory fluorescence decay after exocytosis is lost72. Thus, the newly exocytosed vesicle labels remain on the cell surface while other proteins are endocytosed. The endocytosis of proteins that were on the plasma membrane before exocytosis cannot be explained by kiss-and-run, but kiss-and-run could contribute to the protease-insensitive component of post-exocytosis fluorescence decay.

Another argument against kiss-and-run at synapses has been based on molecular occlusion experiments. Knocking down clathrin eliminates all synaptic-vesicle recycling, and this has been interpreted as suggesting that nerve terminals recycle their synaptic vesicles by a single mechanism that depends on the well-established clathrin pathway of endocytosis73. Studies in the Drosophila neuromuscular junction have shown that with a temperature-sensitive mutant allele of dynamin, called shibire, the restrictive temperature leads to a virtually total loss of vesicles by blocking recycling74,75. Hence, at these synapses, all vesicles can enter a fusion pathway that culminates in complete fusion and collapse. But a key question with both the clathrin and the dynamin experiments remains: do synaptic vesicles enter only the full-fusion pathway, or can they access another pathway, such as kiss-and-run, one or more times before they commit to the full-fusion pathway? In the shibire experiments, the flies were exposed to the restrictive temperature for $5 \mathrm{~min}$, leaving ample time for vesicles to undergo one or more rounds of kiss-and-run before entering the irreversible path to full fusion. This reservation applies to most of the studies based on disruption of endocytosis. What is clearly needed are ways to disrupt the endocytic machinery with temporal precision -using, for example, chromophore assisted photoinactivation76.

More direct studies of exocytosis make a strong case for kiss-and-run at nerve terminals. Unitary release events with a time course consistent with the presence of a fusion pore intermediate have been reported at the Drosophila neuromuscular junction, and manipulations of synaptotagmin alter the time course of these events in a manner consistent with an effect on fusion pores77. Kiss-and-run events were revealed by capacitance recordings from nerve terminals, which showed that stepwise capacitance increases are rapidly followed by precisely matching stepwise capacitance decreases4, 17 . In studies of FM1-43 destaining at synapses, some vesicles lose only a fraction of their label, indicating that a fusion pore restricts the efflux of dye molecules49,78. These studies of the release of single vesicles confirm that nerve terminals have two modes of exocytosis, full fusion and kiss-and-run21. These direct experimental approaches have the capability to illuminate fusion pore properties at synapses.

\section{Biological ramifications}

The fusion pores of $\mathrm{Ca}^{2+}$-triggered exocytosis are dynamic structures that can regulate the form and speed of release of chemical signals. A fusion pore can act as a sieve to limit or prevent the release of different cargo molecules depending on size. For example, moderate stimulation of chromaffin cells triggers the release of only norepinephrine, but stronger stimulation triggers the release of larger neuropeptides as well79. This selectivity is achieved by favoring kiss-and-run with weaker stimulation, leading to fusion pores that are 
too small to pass neuropeptides. Stronger stimulation shifts the mode of release to full fusion such that larger cargo molecules can also be secreted.

Synaptic vesicles contain neurotransmitters that generally are small molecules. At present, there is no indication that synaptic-vesicle fusion pores can regulate what kind of molecules can exit, but fusion pore size is widely believed to determine the rate with which neurotransmitter floods the synaptic cleft. A simple diffusion calculation shows that small fusion pores will not allow the subsynaptic neurotransmitter concentration to rise to that needed for the activation of synaptic receptors 80 , and this has been verified by more detailed numerical 81,82 and analytical 83 treatments. However, there is at present no experiment that explicitly tests the relationship between fusion pore properties (dimensions and dynamics) and a synaptic response (magnitude and time course). Thus, until fusion pores can be manipulated at a synapse and the consequences for synaptic function studied, we will not know how a fusion pore can influence synaptic function.

A consideration of how a small fusion pore would limit neuro-transmitter release prompted the speculation that kiss-and-run could serve as an inhibitory signal in which low levels of neurotransmitter desensitize receptors and make synapses less responsive to an ensuing fullfusion event $4,18,48$. This suggests that a new class of electrophysiological experiments will be needed to test the impact of a previous kiss-and-run event on a subsequent full-fusion event. Thus, the debate about kiss-and-run exocytosis impinges on basic questions of molecular mechanism, as well as questions about the regulation of secretion and the processing of information by neural circuits.

\section{Acknowledgments}

This work was supported by US National Institutes of Health grants to M.B.J. (NS30016 and NS44057) and by US National Institutes of Health (National Institute of General Medical Sciences GM56827 and National Institute of Mental Health MH61876) and American Heart Association (0440168N) grants to E.R.C. E.R.C. is supported by the Howard Hughes Medical Institute.

\section{References}

1. Chandler DE, Heuser JE. Arrest of membrane fusion events in mast cells by quick-freezing. J Cell Biol. 1980; 86:666-674. [PubMed: 7400221]

2. Heuser JE, Reese TS. Structural changes after transmitter release at the frog neuromuscular junction. J Cell Biol. 1981; 88:564-580. [PubMed: 6260814]

3. Lindau M, Almers W. Structure and function of fusion pores in exocytosis and ectoplasmic membrane fusion. Curr Opin Cell Biol. 1995; 7:509-517. [PubMed: 7495570]

4. Klyachko VA, Jackson MB. Capacitance steps and fusion pores of small and large-dense-core vesicles in nerve terminals. Nature. 2002; 418:89-92. This study revealed capacitance steps of small clear vesicles and showed that they undergo kiss-and-run by forming much smaller fusion pores. [PubMed: 12097912]

5. Breckenridge LJ, Almers W. Currents through the fusion pore that forms during exocytosis of a secretory granule. Nature. 1987; 328:814-817. The first measurement of fusion pore conductance gave a value in the range of ion-channel conductances. [PubMed: 2442614]

6. Alvarez de Toledo G, Fernandez-Chacon R, Fernandez JM. Release of secretory products during transient vesicle fusion. Nature. 1993; 363:554-558. [PubMed: 8505984]

7. Chow RH, von Rüden L, Neher E. Delay in vesicle fusion revealed by electrochemical monitoring of single secretory events in adrenal chromaffin cells. Nature. 1992; 356:60-63. This study showed that the contents of a vesicle can trickle out of a fusion pore before full fusion. [PubMed: 1538782]

8. Jankowski JA, Schroeder TJ, Ciolkowski EL, Wightman RM. Temporal characteristics of quantal secretion of catecholamines from adrenal medullary cells. J Biol Chem. 1993; 268:14694-14700. [PubMed: 8325848] 
9. Han X, Jackson MB. Structural transitions in the synaptic SNARE complex during $\mathrm{Ca}^{2+}$-triggered exocytosis. J Cell Biol. 2006; 172:281-293. [PubMed: 16418536]

10. Zhang Z, Jackson MB. Temperature dependence of fusion kinetics and fusion pores in $\mathrm{Ca}^{2+}$ triggered exocytosis from PC12 cells. J Gen Physiol. 2008; 131:117-124. [PubMed: 18195388]

11. Spruce AE, Breckenridge LJ, Lee AK, Almers W. Properties of the fusion pore that forms during exocytosis of a mast cell secretory granule. Neuron. 1990; 4:643-654. [PubMed: 2344404]

12. Zhou Z, Misler S, Chow RH. Rapid fluctuations in transmitter release from single vesicles in bovine adrenal chromaffin cells. Biophys J. 1996; 70:1543-1552. [PubMed: 8785312]

13. Ales E, et al. High calcium concentrations shift the mode of exocytosis to the kiss-and-run mechanism. Nat Cell Biol. 1999; 1:40-44. [PubMed: 10559862]

14. Neher E, Marty A. Discrete changes of cell membrane capacitance observed under conditions of enhanced secretion in bovine adrenal chromaffin cells. Proc Natl Acad Sci USA. 1982; 79:67126716. Besides opening up the study of exocytosis to electrical measurements, this paper was the first report of capacitance flickers, one of the hallmarks of kiss-and-run. [PubMed: 6959149]

15. Fernandez JM, Neher E, Gomperts BD. Capacitance measurements reveal stepwise fusion events in degranulating mast cells. Nature. 1984; 312:453-455. [PubMed: 6504157]

16. Lollike K, Borregaard N, Lindau M. The exocytotic fusion pore of small granules has a conductance similar to an ion channel. J Cell Biol. 1995; 129:99-104. [PubMed: 7535305]

17. He L, Wu XS, Mohan R, Wu LG. Two modes of fusion pore opening revealed by cell-attached recordings at a synapse. Nature. 2006; 444:102-105. [PubMed: 17065984]

18. Wang CT, et al. Different domains of synaptotagmin control the choice between kiss-and-run and full fusion. Nature. 2003; 424:943-947. [PubMed: 12931189]

19. Wang CT, Bai J, Chang PY, Chapman ER, Jackson MB. Synaptotagmin-Ca ${ }^{2+}$ triggers two sequential steps in regulated exocytosis in rat PC12 cells: fusion pore opening and fusion pore dilation. J Physiol (Lond). 2006; 570:295-307. [PubMed: 16293646]

20. Meldolesi J, Ceccarelli B. Exocytosis and membrane recycling. Phil Trans R Soc Lond B. 1981; 296:55-65. [PubMed: 6121347]

21. Valtorta F, Meldolesi J, Fesce R. Synaptic vesicles: is kissing a matter of competence? Trends Cell Biol. 2001; 11:324-328. [PubMed: 11489637]

22. Jackson MB, Chapman ER. Fusion pores and fusion machines in $\mathrm{Ca}^{2+}$-triggered exocytosis. Annu Rev Biophys Biomol Struct. 2006; 35:135-160. [PubMed: 16689631]

23. Kozlov MM, Leikin SL, Chernomordik LV, Markin VS, Chizmadzhev YA. Stalk mechanism of vesicle fusion. Intermixing of aqueous contents. Eur Biophys J. 1989; 17:121-129. [PubMed: 2792021]

24. Chanturiya A, Chernomordik LV, Zimmerberg J. Flickering fusion pores comparable with initial exocytotic pores occur in protein-free phospholipid bilayers. Proc Natl Acad Sci USA. 1997; 94:14423-14428. [PubMed: 9405628]

25. Lee J, Lentz BR. Evolution of lipidic structures during model membrane fusion and the relation of this process to cell membrane fusion. Biochemistry. 1997; 36:6251-6259. [PubMed: 9174340]

26. Yang L, Huang HW. Observation of a membrane fusion intermediate structure. Science. 2002; 297:1877-1879. [PubMed: 12228719]

27. Weber T, et al. SNAREpins: minimal machinery for membrane fusion. Cell. 1998; 92:759-772. [PubMed: 9529252]

28. Xu Y, Zhang F, Su Z, McNew JA, Shin YK. Hemifusion in SNARE-mediated membrane fusion. Nat Struct Mol Biol. 2005; 12:417-422. [PubMed: 15821745]

29. Yoon TY, Okumus B, Zhang F, Shin YK, Ha T. Multiple intermediates in SNARE-induced membrane fusion. Proc Natl Acad Sci USA. 2006; 103:19731-19736. [PubMed: 17167056]

30. Abdulreda MH, Bhalla A, Chapman ER, Moy VT. Atomic force microscope spectroscopy reveals a hemifusion intermediate during soluble $\mathrm{N}$-ethylmaleimide-sensitive factor-attachment protein receptors-mediated membrane fusion. Biophys J. 2008; 94:648-655. [PubMed: 17872963]

31. Liu T, Wang T, Chapman ER, Weisshaar JC. Productive hemifusion intermediates in fast vesicle fusion driven by neuronal SNAREs. Biophys J. 2008; 94:1303-1314. [PubMed: 17951297] 
32. Jun Y, Wickner W. Assays of vacuole fusion resolve the stages of docking, lipid mixing, and content mixing. Proc Natl Acad Sci USA. 2007; 104:13010-13015. [PubMed: 17664431]

33. Reese $\mathrm{C}$, Heise F, Mayer A. Trans-SNARE pairing can precede a hemifusion intermediate in intracellular membrane fusion. Nature. 2005; 436:410-414. [PubMed: 15924133]

34. Reese C, Mayer A. Transition from hemifusion to pore opening is rate limiting for vacuole membrane fusion. J Cell Biol. 2005; 171:981-990. [PubMed: 16365164]

35. Giraudo CG, et al. SNAREs can promote complete fusion and hemifusion as alternative outcomes. J Cell Biol. 2005; 170:249-260. [PubMed: 16027221]

36. Wong JL, Koppel DE, Cowan AE, Wessel GM. Membrane hemifusion is a stable intermediate of exocytosis. Dev Cell. 2007; 12:653-659. [PubMed: 17420001]

37. Chernomordik LV, Kozlov MM. Protein-lipid interplay in fusion and fission of biological membranes. Annu Rev Biochem. 2003; 72:175-207. [PubMed: 14527322]

38. Cohen FS, Melikyan GB. The energetics of membrane fusion from binding, through hemifusion, pore formation, and pore enlargement. J Membr Biol. 2004; 199:1-14. [PubMed: 15366419]

39. Kemble GW, Danieli T, White JM. Lipid-anchored influenza hemagglutinin promotes hemifusion, not complete fusion. Cell. 1994; 76:383-391. [PubMed: 8293471]

40. Nussler F, Clague MJ, Herrmann A. Meta-stability of the hemifusion intermediate induced by glycosylphosphatidylinositol-anchored influenza hemagglutinin. Biophys J. 1997; 73:2280-2291. [PubMed: 9370425]

41. Markosyan RM, Cohen FS, Melikyan GB. The lipid-anchored ectodomain of influenza virus hemagglutinin (GPI-HA) is capable of inducing nonenlarging fusion pores. Mol Biol Cell. 2000; 11:1143-1152. [PubMed: 10749920]

42. Tse FW, Iwata A, Almers W. Membrane flux through the pore formed by a fusogenic viral envelope protein during cell fusion. J Cell Biol. 1993; 121:543-552. [PubMed: 8486735]

43. Zimmerberg J, Blumenthal R, Curran M, Sarker D, Morris S. Restricted movement of lipid and aqueous dyes through pores formed by influenza hemagglutinin during cell fusion. J Cell Biol. 1994; 127:1885-1894. [PubMed: 7806567]

44. Chernomordik LV, Frolov VA, Leikina E, Bronk P, Zimmerberg J. The pathway of membrane fusion catalyzed by influenza hemagglutinin: restriction of lipids, hemifusion, and lipidic fusion pore formation. J Cell Biol. 1998; 140:1369-1382. [PubMed: 9508770]

45. Lollike K, Borregaard N, Lindau M. Capacitance flickers and pseudoflickers of small granules, measured in the cell-attached configuration. Biophys J. 1998; 75:53-59. [PubMed: 9649367]

46. Monck JR, Alvarez de Toledo G, Fernandez JM. Tension in secretory granule membranes causes extensive membrane transfer through the exocytotic fusion pore. Proc Natl Acad Sci USA. 1990; 87:7804-7808. [PubMed: 2235997]

47. Oberhauser AF, Monck JR, Fernandez JM. Events leading to the opening and closing of the exocytotic fusion pore have markedly different temperature dependencies. Kinetic analysis of single fusion events in patch-clamped mouse mast cells. Biophys J. 1992; 61:800-809. [PubMed: 1504250]

48. Taraska JW, Almers W. Bilayers merge even when exocytosis is transient. Proc Natl Acad Sci USA. 2004; 101:8780-8785. [PubMed: 15173592]

49. Richards DA, Bai J, Chapman ER. Two modes of exocytosis at hippocampal synapses revealed by rate of FM1-43 efflux from individual vesicles. J Cell Biol. 2005; 168:929-939. [PubMed: 15767463]

50. Han X, Wang CT, Bai J, Chapman ER, Jackson MB. Transmembrane segments of syntaxin line the fusion pore of $\mathrm{Ca}^{2+}$-triggered exocytosis. Science. 2004; 304:289-292. The first study to locate a molecule, syntaxin, as a structural component of a fusion pore in $\mathrm{Ca}^{2+}$-triggered exocytosis. [PubMed: 15016962]

51. Han X, Jackson MB. Electrostatic interactions between the syntaxin membrane anchor and neurotransmitter passing through the fusion pore. Biophys J. 2005; 88:L20-L22. [PubMed: 15653732]

52. Barclay JW, Aldea M, Craig TJ, Morgan A, Burgoyne RD. Regulation of the fusion pore conductance during exocytosis by cyclin-dependent kinase 5. J Biol Chem. 2004; 279:4149541503. [PubMed: 15273248] 
53. Sorensen JB, et al. Differential control of the releasable vesicle pools by SNAP-25 splice variants and SNAP-23. Cell. 2003; 114:75-86. [PubMed: 12859899]

54. Sorensen JB, et al. Sequential N- to C-terminal SNARE complex assembly drives priming and fusion of secretory vesicles. EMBO J. 2006; 25:955-966. [PubMed: 16498411]

55. Kesavan J, Borisovska M, Bruns D. v-SNARE actions during $\mathrm{Ca}^{2+}$-triggered exocytosis. Cell. 2007; 131:351-363. [PubMed: 17956735]

56. Edwardson JM, et al. Expression of mutant huntingtin blocks exocytosis in PC12 cells by depletion of complexin II. J Biol Chem. 2003; 278:30849-30853. [PubMed: 12807877]

57. Hatsuzawa K, Lang T, Fasshauer D, Bruns D, Jahn R. The R-SNARE motif of tomosyn forms SNARE core complexes with syntaxin 1 and SNAP-25 and down-regulates exocytosis. J Biol Chem. 2003; 278:31159-31166. [PubMed: 12782620]

58. Yizhar O, et al. Tomosyn inhibits priming of large dense-core vesicles in a calcium-dependent manner. Proc Natl Acad Sci USA. 2004; 101:2578-2583. [PubMed: 14983051]

59. Borisovska M, et al. v-SNAREs control exocytosis of vesicles from priming to fusion. EMBO J. 2005; 24:2114-2126. [PubMed: 15920476]

60. Wang CT, et al. Synaptotagmin modulation of fusion pore kinetics in regulated exocytosis of dense-core vesicles. Science. 2001; 294:1111-1115. [PubMed: 11691996]

61. Bai J, Wang CT, Richards DA, Jackson MB, Chapman ER. Fusion pore dynamics are regulated by synaptotagmin.t-SNARE interactions. Neuron. 2004; 41:929-942. [PubMed: 15046725]

62. Constable JR, Graham ME, Morgan A, Burgoyne RD. Amisyn regulates exocytosis and fusion pore stability by both syntaxin-dependent and syntaxin-independent mechanisms. J Biol Chem. 2005; 280:31615-31623. [PubMed: 16033762]

63. Sombers LA, et al. The effects of vesicular volume on secretion through the fusion pore in exocytotic release from PC12 cells. J Neurosci. 2004; 24:303-309. [PubMed: 14724228]

64. Fisher RJ, Pevsner J, Burgoyne RD. Control of fusion pore dynamics during exocytosis by Munc18. Science. 2001; 291:875-878. [PubMed: 11157167]

65. Barclay JW. Munc-18-1 regulates the initial release rate of exocytosis. Biophys J. 2008; 94:10841093. [PubMed: 17921224]

66. Graham ME, Burgoyne RD. Comparison of cysteine string protein (Csp) and mutant $\alpha$-SNAP overexpression reveals a role for Csp in late steps of membrane fusion in dense-core granule exocytosis in adrenal chromaffin cells. J Neurosci. 2000; 20:1281-1289. [PubMed: 10662817]

67. Archer DA, Graham ME, Burgoyne RD. Complexin regulates the closure of the fusion pore during regulated vesicle exocytosis. J Biol Chem. 2002; 277:18249-18252. [PubMed: 11929859]

68. Neco P, et al. Myosin II contributes to fusion pore expansion during exocytosis. J Biol Chem. 2008; 283:10949-10957. [PubMed: 18283106]

69. Granseth B, Odermatt B, Royle SJ, Lagnado L. Clathrin-mediated endocytosis is the dominant mechanism of vesicle retrieval at hippocampal synapses. Neuron. 2006; 51:773-786. [PubMed: 16982422]

70. Balaji J, Ryan TA. Single-vesicle imaging reveals that synaptic vesicle exocytosis and endocytosis are coupled by a single stochastic mode. Proc Natl Acad Sci USA. 2007; 104:20576-20581. [PubMed: 18077369]

71. Gandhi SP, Stevens CF. Three modes of synaptic vesicular recycling revealed by single-vesicle imaging. Nature. 2003; 423:607-613. [PubMed: 12789331]

72. Wienisch M, Klingauf J. Vesicular proteins exocytosed and subsequently retrieved by compensatory endocytosis are nonidentical. Nat Neurosci. 2006; 9:1019-1027. [PubMed: 16845386]

73. Granseth B, Odermatt B, Royle SJ, Lagnado L. Clathrin-mediated endocytosis the physiological mechanism of vesicle retrieval at hippocampal synapses. J Physiol (Lond). 2007; 585:681-686. [PubMed: 17599959]

74. Koenig JH, Ikeda K. Disappearance and reformation of synaptic vesicle membrane upon transmitter release observed under reversible blockage of membrane retrieval. J Neurosci. 1989; 9:3844-3860. [PubMed: 2573698] 
75. Koenig JH, Saito K, Ikeda K. Reversible control of synaptic transmission in a single gene mutant of Drosophila melanogaster. J Cell Biol. 1983; 96:1517-1522. [PubMed: 6304107]

76. Poskanzer KE, Marek KW, Sweeney ST, Davis GW. Synaptotagmin I is necessary for compensatory synaptic vesicle endocytosis in vivo. Nature. 2003; 426:559-563. [PubMed: 14634669]

77. Pawlu C, DeAntonio A, Heckmann M. Postfusional control of quantal current shape. Neuron. 2004; 42:607-618. This study suggested that fusion pores could shape a synaptic current. [PubMed: 15157422]

78. Aravanis AM, Pyle JL, Tsien RW. Single synaptic vesicles fusing transiently and successively without loss of identity. Nature. 2003; 423:643-647. The first clear evidence for kiss-and-run at synapses. [PubMed: 12789339]

79. Fulop T, Radabaugh S, Smith C. Activity-dependent differential transmitter release in mouse adrenal chromaffin cells. J Neurosci. 2005; 25:7324-7332. This study suggested that fusion pores, and the mode of release, can select different molecules within a vesicle for exocytosis. [PubMed: 16093382]

80. Khanin R, Parnas H, Segel L. Diffusion cannot govern the discharge of neuro-transmitter in fast synapses. Biophys J. 1994; 67:966-972. [PubMed: 7811953]

81. Clements JD. Transmitter timecourse in the synaptic cleft: its role in central synaptic function. Trends Neurosci. 1996; 19:163-171. [PubMed: 8723198]

82. Stiles JR, Van Helden D, Bartol TM, Salpeter EE, Salpeter MM. Miniature endplate current rise times $<100 \mu$ s from improved dual recordings can be modeled with passive acetylcholine diffusion from a synaptic vesicle. Proc Natl Acad Sci USA. 1996; 93:5747-5752. [PubMed: 8650164]

83. Jackson MB. In search of the fusion pore of exocytosis. Biophys Chem. 2007; 126:201-208. [PubMed: 16797829] 
a

i
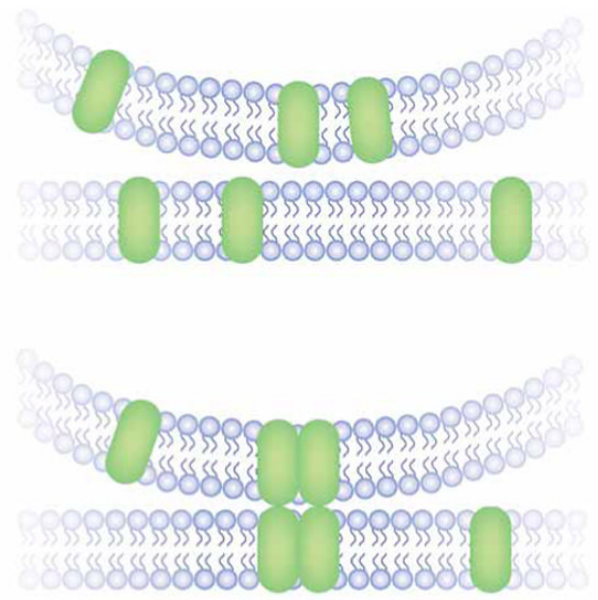

iii

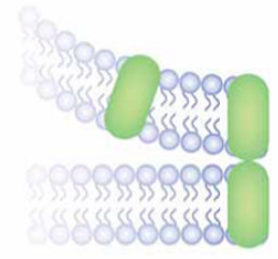

iv
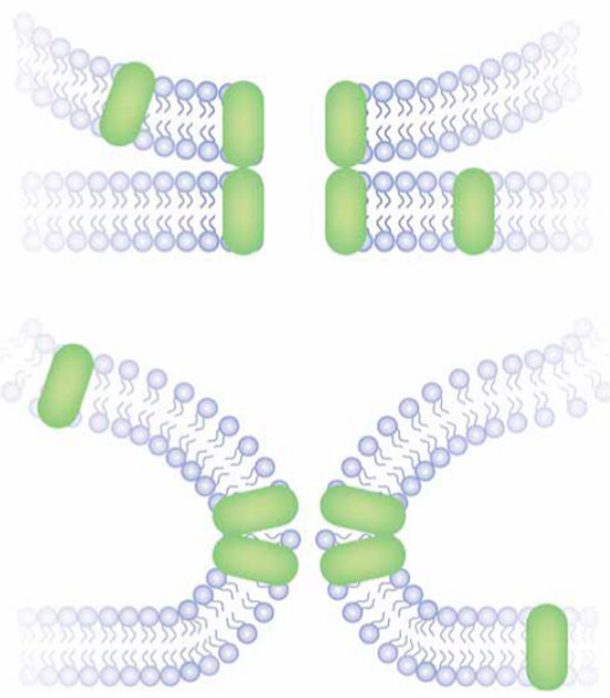

b

i

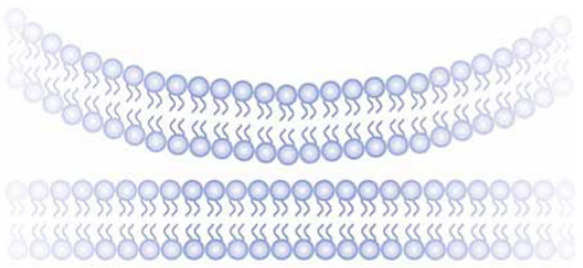

ii

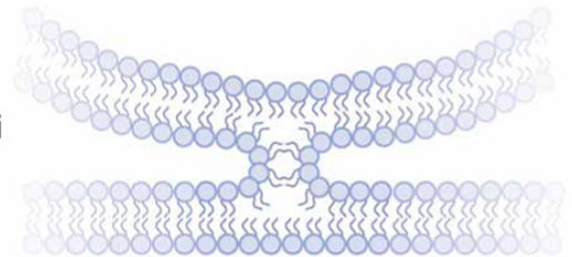

iii
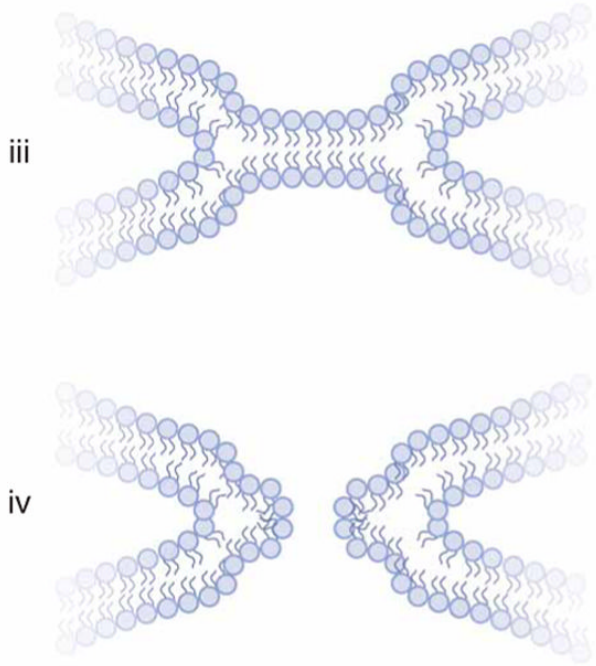

Figure 1.

Two models of membrane fusion. (a, i) Proteins capable of forming a fusion pore are present in the vesicle and plasma membranes. (ii) These proteins associate into a closed pore. (iii) A conformational change in this complex opens the pore. (iv) The lipid bilayers merge through a remodeling of the two lipid bilayers. (b) Lipid fusion according to the stalk model23. (i) Lipid bilayers are pulled together. In regulated exocytosis, proteins (not shown) exert the necessary force. (ii) An initial merger stage forms, in which the outer leaflets remodel to form a stalk. (iii) The outer leaflets draw apart and the inner leaflets form a bilayer in this hemifusion diaphragm. (iv) A pore forms in the new bilayer of inner leaflets. 

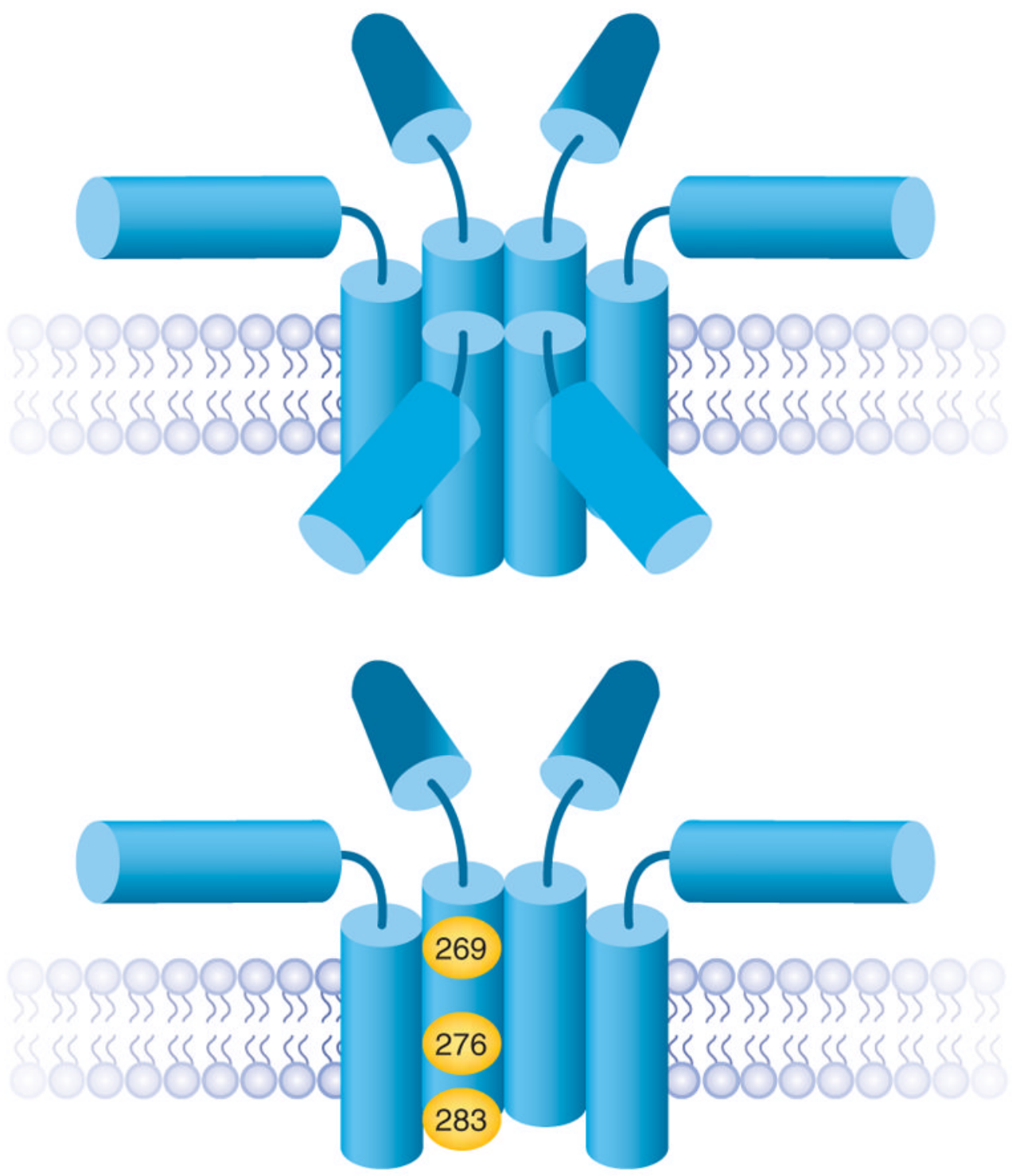

Figure 2.

A model of the fusion pore formed by the membrane anchors of syntaxin48. A barrel of five to eight membrane anchors can form a fusion pore with a conductance consistent with experimental measurements; six are shown here (top). The SNARE motifs radiate outward from the pore. The fusion pore through the vesicle membrane and the t-SNARE components are not shown. The residues where mutations alter fusion pore flux and conductance fall along one face of a helical wheel formed from the membrane anchor. Residues implicated as lining the pore are highlighted in yellow (bottom). 